\title{
An Improved Approach for Constructing the Real Estate Price Index with Bargaining Effect
}

\author{
Yunyi Zhang ${ }^{1,2}$ \& Huaying $\mathrm{Gu}^{3}$ \\ ${ }^{1}$ Harbin Institute of Technology Shenzhen Graduate School, Shenzhen, China \\ ${ }^{2}$ Center for Assessment and Development Research of Real Estate, Shenzhen, China \\ ${ }^{3}$ Logistics Research Center, Shanghai Maritime University, Shanghai, China \\ Correspondence: Y. Zhang, Center for Assessment and Development Research of Real Estate, Hongli West Road \\ 8007, 518000 Shenzhen, China. Tel: 86-182-0272-0921. E-mail: zhangyunyi920@qq.com
}

Received: February 19, 2020

Accepted: March 10, 2020

Online Published: March 30, 2020

doi:10.5539/ijef.v12n5p1

URL: https://doi.org/10.5539/ijef.v12n5p1

\begin{abstract}
Bargaining game is ubiquitous in real estate markets due to its heterogeneity. Price index, the most important measurement the market condition, constructed with current approaches however cannot consider the effect of bargaining. Therefore, in this work, we provide a construction of price index including sellers' bargaining power based on Nash bargaining theory and Heckman's two-step regression. The sellers' bargaining power is estimated from the aggregate data of list-price, sale-price and time-on-the-market. Using this method, the residential price index of an empirical example was conducted. The results are in reasonable agreement with the realistic situations, verifying the feasibility and applicability of the developed method.
\end{abstract}

Keywords: price index, bargaining, residential real estate

\section{Introduction}

No one can deny that the real estate industry is important on the national economy, which connects the upstream and downstream industries and affects the huge employment populations. From daily consumption to finance, it is closely related to real estate. A house is so important for one obvious and primary reason: it is the single most important purchase that most of us make in our lives, and a large part of our happiness comes from it. With a house, many incidental expenses can be realized such as the furniture decoration. Furthermore, the housing price and some social problems such as marriage, fertility, population growth and financial stability are interdependent (He \& Wen, 2017; Wen \& He, 2015; Liu, Zheng, Zhao, \& Wang, 2020). Therefore, studying and monitoring the trading situation of residential real estate is of great significance such as real estate bubble warning (Zhou, 2008). One measurement of the state of market is the price index, which not only measures the past state of housing market but also possess predictability of its growth rate (Yang, Long, Peng, \& Cai, 2020). There are three commonly used methods to construct the price indices, namely Hedonic-regression (Rosen, 1974), repeated-sales models (Bailey, Muth, \& Nourse, 1963; Francke, 2010; Francke \& Minne, 2017) and hybrid approaches (Wallace \& Meese, 1997). However, these price indices do not consider the randomness of housing transaction and data selection that may cause sample selection bias. Gatzlaff et al. (1997; 1998) and Munneke et al. $(2000 ; 2001)$ found that the selection bias can be corrected by the inclusion of inverse Mills ratio, derived from the Heckman's two-step approach (Heckman, 1979). This method has been widely applied to the residential and commercial housing market analyses (Heckman, 1979; Li \& Chau, 2016).

Another important gauge of the state of market is the liquidity, generally being reflected by the probability of sale (Krainer, 2001; Krainer \& LeRoy, 2002; Selcuk, 2013; Fisher, Gatzlaff, Geltner, \& Haurin, 2003). It has been recognized that the liquidity has endogenous relationship with transaction price (Fisher et al., 2003; Fisher, Geltner, \& Pollakowski, 2007). There are two sides of agents attending in a residential real estate market, i.e., potential buyers and potential sellers holding their own reservation prices. Sellers want money and sell their assets to buyers, while buyers bring money or liquidity into the market (Dijk, Geltner, \& Minne, 2018). The relative movement of sellers' and buyers' reservation prices over time shows the transaction volume or liquidity (Fisher et al., 2003; Genesove, 2012; Zheng, Chau, \& Eddie, 2015; Gong, Zhang, \& Zhao, 2018). Specifically, in upward market period the increase of sellers' and buyers' reservation prices drives the increase of the transaction 
price, while the greater increase of buyers' reservation price than that of buyers leads to more trading or liquidity; Similarly, in downward market the decrease of sellers' and buyers' reservation prices reduces the transaction price, while the greater decrease of buyers' reservation price than that of sellers results in less trading or liquidity (Gong et al., 2018).

To generates a more comprehensive indicator of the state of market, a demand-side "constant liquidity" price index is proposed (Fisher et al., 2003), which collapses the two dimensions of price and liquidity to a single dimension of liquidity-adjusted price. This price index is an extension beyond Heckman's two-step approach by adding additional corrections from the outputs of regression. The "constant liquidity" represents a special case that the sellers match the change of buyers' reservation prices, then the transaction volume or liquidity will be equal over time, and the transaction price change is tracked by the buyer reservation price index. To achieve a deal, the buyers' reservation price should be larger than that of sellers (Fisher et al., 2003; Zheng et al., 2015; Lin \& Vandell, 2007), since the reservation prices of sellers and buyers are the minimum and maximum prices that they are willing to accept in a transaction, respectively. In the construction process of Fisher et al. (2003), the transaction price is assumed at the midpoint between buyers' and sellers' reservation price. Nonetheless, the bargaining game exists in the transactions not only limited in the commercial company (Devarakonda, Reuer, \& Tadikonda, 2016) but also personal consultation. As for a house, the buyers and sellers would bargain over the price based on the evaluation of the house affected by some externalities such traffic location, school district, landfill site ( $\mathrm{Li} \& \mathrm{Li}, 2018$ ), and so forth. Therefore, the ultimate price could be anywhere between buyers' and sellers' reservation prices, as a result of the bargaining game between the two-sided participants (Harding, Rosenthal, \& Sirmans, 2003). This has been demonstrated by empirical researches (Harding et al., 2003; Merlo \& Ortalo-Magne, 2004). Harding et al. (2003) analyzed the effect of different demographic traits, such as household wealth and gender, on bargaining power by adding characteristics of buyers and sellers to a hedonic model. Rather differently, Carrillo (2013) presented an index that measures the seller's bargaining power by using individual-level or aggregate data, which thus can be easily adopted in the construction of price index.

From the above review, we note that despite the definite existence of bargaining effect in the transaction of housing market, its crucial role has been overlooked in all current price index models. Therefore, the key substance and innovation of our work is to develop an approach which can account for the bargaining effect beyond current methods. Additionally, the improved approach still can be conveniently performed in the framework of current methods, that is to say, it is a user-friendly method, and a more complete and general method. The implementation of the improved price index model is provided and its feasibility is examined. Taking as an example, we use this price index to study the housing market of Shanghai, China. The required individual-level data such as list prices, sale prices, time on the market, share of transactions below the list price, and many others, are collected from a database system of a real estate agent well-known in China as the Homelink Real Estate (HRE). Compared with developed countries, the informatization development of Chinese real estate market is relatively late. The data of individual transactions can only be available since 2011. The remainder of this paper is organized as follows: in the second section, we analyze the ultimate sale price by Nash bargaining theory combined the buyer-seller relative bargaining power, and developed the models for constructing the price index; in the third section, the empirical results and discussions are given; in the final section, the study of this work is concluded.

\section{Method}

\subsection{Ultimate Sale Price}

The ultimate sale price can be determined from Nash bargaining based on the fact that buyers and sellers split the surplus in the transaction depending on their relative bargaining power, which can be expressed as

$$
\max _{p \in\left[R_{i t}^{S}, R_{i t}^{b}\right]} \Pi\left(P_{i t}\right)=\left(R_{i t}^{b}-P_{i t}\right)^{1-\omega_{t}}\left(P_{i t}-R_{i t}^{S}\right)^{\omega_{t}}
$$

where the $\omega_{t}$ reflects the sellers' bargaining power or negotiating skill relative to the buyers, which should be $0 \leq \omega_{t} \leq 1$. $R_{i t}^{b}$ and $R_{i t}^{s}$ are buyers' and sellers' reservation price for asset $i$ at time $t, R_{i t}^{b}-P_{i t}$ is buyers' utility, and $P_{i t}-R_{i t}^{S}$ is sellers' utility. The first-order derivative equaling to zeros yields the optimal $P_{i t}^{*}$ as

$$
P_{i t}^{*}=\omega_{t} \cdot R_{i t}^{b}+\left(1-\omega_{t}\right) \cdot R_{i t}^{s} \text {. }
$$

Intuitively, the ultimate sale price lies between the double-sided reservation prices. The expression obeys the common sense that the weaker the sellers' bargaining power is, the closer the ultimate sale price is to the sellers' reservation price $R_{i t}^{S}$ and the lower the utility is obtained by sellers.

As has been derived (Carrillo, 2013) that the sellers' bargaining power is a function of mean log list prices $\bar{L}_{t}$, mean $\log$ sale prices $\bar{P}_{t}$, mean number of days that a property stays on the market $\bar{d}_{t}$, and the share of 
transactions that occurred below the list price $\mu_{t}$, as

$$
\omega_{t}=\frac{1}{1+\frac{\mu_{t}}{1-\mu_{t}} \exp \left(\frac{\bar{L}_{t}-\bar{P}_{t}}{\mu_{t}} \lambda\right)\left(\frac{1-\mu_{t}}{1-\mu_{t}+r \bar{d}_{t}}\right)^{1+\frac{1-\mu_{t}}{r}{ }^{\prime}}}
$$

in which the daily discount rate $r$ and the parameter $\lambda$ measuring the buyers' response to the changes in list prices are generally normalized as constants.

\subsection{Price Index Based on Two-Side Negotiation}

To include the sellers' bargaining power, the demand and supply sides need to be separately identified, thus the buyers' and seller's reservation prices are expressed as

$$
\begin{gathered}
R_{i t}^{b}=\sum \alpha_{j}^{b} X_{i j t}^{P}+\sum \beta_{t}^{b} Z_{t}+\varepsilon_{i t}^{b}, \\
R_{i t}^{s}=\sum \alpha_{j}^{s} X_{i j t}^{P}+\sum \beta_{t}^{s} Z_{t}+\varepsilon_{i t}^{s},
\end{gathered}
$$

where $X_{i j t}^{P}$ is a vector of $j$ asset-specific cross-sectional characteristics relevant to valuation, $Z_{t}$ depicts a vector of zero/one time-variable with one representing sold and zero for unsold, $\varepsilon_{i t}^{b}$ and $\varepsilon_{i t}^{s}$ are normally distributed mean zero random errors and reflect heterogeneity within the buyer and seller populations, respectively.

The transaction is consummated if the buyers' reservation price exceeds the sellers, that is $R_{i t}^{b} \geq R_{i t}^{s}$. Therefore, the ultimate sale price is

$$
P_{i t}=\left\{\begin{array}{cl}
\text { observed } & \text { if } R_{i t}^{b}-R_{i t}^{s} \geq 0 \\
\text { unobserved } & \text { if } R_{i t}^{b}-R_{i t}^{s}<0
\end{array} .\right.
$$

Then the expected transaction price is

$$
E\left[P_{i t}\right]=\sum_{j}\left[\left(1-\omega_{t}\right) \alpha_{j}^{b}+\omega_{t} \alpha_{j}^{s}\right] X_{i j t}^{P}+\sum_{t}\left[\omega_{t} \beta_{t}^{b}+\left(1-\omega_{t}\right) \beta_{t}^{s}\right] Z_{t}+E\left[\left[\omega_{t} \varepsilon_{i t}^{b}+\left(1-\omega_{t}\right) \varepsilon_{i t}^{s}\right] \mid R_{i t}^{b} \geq R_{i t}^{s}\right]
$$

and $E\left[P_{i t}\right]$ can be obtained by estimating the following regression

$$
P_{i t}=\sum_{j} a_{j t} X_{i j t}^{P}+\sum_{t} \beta_{t} Z_{t}+\left(\varepsilon_{i t} \mid R_{i t}^{b} \geq R_{i t}^{s}\right)
$$

with $\quad a_{j t}=\omega_{t} \alpha_{j t}^{b}+\left(1-\omega_{t}\right) \alpha_{j t}^{S}, \quad \beta_{t}=\omega_{t} \beta_{t}^{b}+\left(1-\omega_{t}\right) \beta_{t}^{S} \quad$ and $\quad \varepsilon_{i t}=\omega_{t} \varepsilon_{i t}^{b}+\left(1-\omega_{t}\right) \varepsilon_{i t}^{s} \quad$. The original selection-bias-uncorrected residential housing price index can be constructed by the estimation of time-dummy $\beta_{t}$ coefficients.

Since the observed trading sample is not randomly selected in buyer and seller populations, the stochastic error term in Eq. (6) has a nonzero mean. That is, for $R_{i t}^{b} \geq R_{i t}^{S}$, there is $E\left[\left[\omega_{t} \varepsilon_{i t}^{b}+\left(1-\omega_{t}\right) \varepsilon_{i t}^{S}\right] \mid R_{i t}^{b} \geq R_{i t}^{S}\right] \neq 0$. Simple ordinary least squares (OLS) estimation of Eq. (7) leads to biased coefficients. This sample selection bias problem can be corrected by the Heckman two-step method (Heckman, 1979; Firsher et al., 2003). In the first step, a probit model of asset sale probability is considered on the basis of a decision that whether to sell or not. The decision for the $i$-th asset in period $t$ is described by the latent variable $S_{i t}^{*}$ which is equal to the difference between the buyer's and seller's reservation prices for the asset, as

$$
S_{i t}^{*}=R_{i t}^{b}-R_{i t}^{S} \text {. }
$$

The latent variable $S_{i t}^{*}$ is not observable, and only the outcome $S_{i t}$ is known as

$$
S_{i t}=\left\{\begin{array}{ll}
1, & \text { if } S_{i t}^{*} \geq 0 \\
0, & \text { otherwise }
\end{array} .\right.
$$

In another word, a sale would occur only when $R_{i t}^{b} \geq R_{i t}^{s}$, in which case $S_{i t}=1$, otherwise $S_{i t}=0$. Substituting Eq. (4) into Eq. (8), it is obtained that

$$
S_{i t}^{*}=\sum\left(\alpha_{j}^{b}-\alpha_{j}^{s}\right) X_{i j t}^{P}+\sum\left(\beta_{t}^{b}-\beta_{t}^{s}\right) Z_{t}+\left(\varepsilon_{i t}^{b}-\varepsilon_{i t}^{s}\right) .
$$

Let's define $\lambda_{j}=\alpha_{j}^{b}-\alpha_{j}^{s}, \gamma_{t}=\beta_{t}^{b}-\beta_{t}^{s}$ and $\eta_{i t}=\varepsilon_{i t}^{b}-\varepsilon_{i t}^{s}$. Eqs. (9) and (10) can be estimated as a probit model

$$
\operatorname{Pr}\left[S_{i t}=1\right]=\Phi\left[\sum \lambda_{j} X_{i j t}^{P}+\sum \gamma_{t} Z_{t}\right]
$$

where $\Phi[\cdot]$ is the cumulative density function of normal a probability distribution. The scale factor of the coefficients and the residuals are estimated. The estimated coefficient is $\frac{\gamma_{t}}{\sigma}$ and the estimated error is $\frac{\eta_{i t}}{\sigma}$ with $\sigma^{2}=\operatorname{Var}\left(\varepsilon_{i t}^{b}-\varepsilon_{i t}^{s}\right)$. If labeling the estimated probit coefficient as $\hat{\gamma}_{t}$, then $\hat{\gamma}_{t}=\frac{\gamma_{t}}{\widehat{\sigma}}=\frac{\left(\widehat{\beta}_{t}^{b}-\widehat{\beta}_{t}^{s}\right)}{\widehat{\sigma}}$. According to the estimated results of the probit, the inverse Mills ratio $\left(\lambda_{i t}\right)$ can be created. In the second step, using the explanatory variables listed in Eq. (7) and $\lambda_{i t}$ to estimate an OLS hedonic price equation, there is

$$
P_{i t}=\sum a_{j} X_{i j t}^{P}+\sum \beta_{t} Z_{t}+\sigma_{\varepsilon \eta} \lambda_{i t}+v_{i t}
$$


where $\sigma_{\varepsilon \eta}$ equals to the covariance of the errors in Eqs. (7) and (11). The error term $v_{i t}$ has zero mean. The estimation of coefficients $\beta_{t}$ trace out the selection-corrected price index.

In the last step, we integrate the changes in the mean of the buyers' reservation price distributions, the dependence on time of which is

$$
V_{i t}-V_{i t-1}=\sum \alpha_{j}^{b}\left(X_{i j t}^{P}-X_{i j t-1}^{P}\right)+\beta_{t}^{b}-\beta_{t-1}^{b},
$$

where the coefficients $\beta_{t}^{b}$ trace out the demand-side price index. Similar to Eq. (7), from the calculation of expected transaction price in Eq. (6) and the estimated coefficients $\hat{\beta}_{t}$ in Eq. (10), the estimation of $\beta_{t}^{b}$ can be obtained as

$$
\hat{\beta}_{t}^{b}=\frac{1}{\omega_{t}} \hat{\beta}_{t}-\frac{1-\omega_{t}}{\omega_{t}} \hat{\beta}_{t}^{s}
$$

Based on the probit estimation Eq. (11) and its underlying Eq. (8), there is

$$
\hat{\gamma}_{t}=\frac{\left(\widehat{\beta}_{t}^{b}-\widehat{\beta}_{t}^{S}\right)}{\widehat{\sigma}} .
$$

For a known $\hat{\sigma}$, after solving Eqs. (14) and (15), we obtain the demand-side index as

$$
\hat{\beta}_{t}^{b}=\hat{\beta}_{t}+\left(1-\omega_{t}\right) \hat{\gamma}_{t} \hat{\sigma} \text {. }
$$

The $\hat{\beta}_{t}$ coefficient is the price index with selection bias corrected while the $\hat{\beta}_{t}^{b}$ is the demand-side price index further containing the bargaining power as compared to $\hat{\beta}_{t}$.

\section{Application to Empirical Analysis}

After constructing the bargaining-included price index, we demonstrate its practical operability in an examination study of the residential real estate market of Shanghai, China. The data are obtained from the China HomeLink Real Estate Network, and the annual data from 2011 to 2018 are used to construct the residential price indices. The data include information of list prices, sale prices, time on the market, and units' property characteristics that people always concerns including the number of bedrooms, number of bathrooms, number of living rooms, number of kitchens and total areas. Moreover, the districts of the units belonging to are also distinguished, considering five representative districts in Shanghai, namely Minhang, Xuhui, Yangpu, Songjiang, and Pudong districts. After removing the missing observations and abnormal data, it yields 187,117 observations

\begin{tabular}{|c|c|c|c|c|c|c|c|}
\hline $\begin{array}{l}\text { Variable } \\
\text { Year } \\
\end{array}$ & $\begin{array}{l}\text { No. of } \\
\text { all Obs. }\end{array}$ & $\begin{array}{l}\text { No. of } \\
\text { UNSOLD }\end{array}$ & No. of SOLD & $\begin{array}{l}\text { SOLD } \\
\text { Mean } \\
\text { Ave. Price }\end{array}$ & $\begin{array}{l}\text { SOLD } \\
\text { Std. Dev. }\end{array}$ & $\begin{array}{l}\text { SOLD } \\
\text { Min } \\
\text { Ave. Price }\end{array}$ & $\begin{array}{l}\text { SOLD } \\
\text { Max } \\
\text { Ave. Price }\end{array}$ \\
\hline 2011 & 251 & 131 & 120 & 39506.9 & 9086.0 & 26021 & 60516 \\
\hline 2012 & 512 & 314 & 198 & 39732.8 & 13146.7 & 12924 & 110379 \\
\hline 2013 & 1,453 & 855 & 598 & 40109.8 & 13108.9 & 5724 & 78957 \\
\hline 2014 & 2,074 & 1,202 & 872 & 40225.8 & 14240.4 & 7815 & 123304 \\
\hline 2015 & 12,840 & 7,723 & 5,117 & 40338.2 & 13501.0 & 12346 & 126120 \\
\hline 2016 & 51,895 & 39,636 & 12,259 & 46463.7 & 16176.3 & 11735 & 141819 \\
\hline 2017 & 62,118 & 44,500 & 17,618 & 51616.1 & 16027.4 & 5799 & 142514 \\
\hline 2018 & 55,974 & 33,729 & 22,245 & 48340.4 & 17397.3 & 11572 & 158277 \\
\hline Total & 187,117 & 128,090 & 59,027 & & & & \\
\hline \multicolumn{8}{|l|}{ Transaction } \\
\hline Ave. List price/Pl & & & & 45727.8 & 10313.1 & 5822 & 161173 \\
\hline Ave. Sale price/Ps & & & & 44165.4 & 16617.4 & 5724 & 158277 \\
\hline Days on the market & & & & 156 & 16.6 & 0 & 366 \\
\hline \multicolumn{8}{|l|}{ Hedonic variable } \\
\hline No. of Bedrooms & & & & 1.97 & 0.78 & 0 & 8 \\
\hline No. of Bathrooms & & & & 1.19 & 0.52 & 0 & 7 \\
\hline No. of Living rooms & & & & 1.15 & 0.44 & 0 & 6 \\
\hline No. of Kitchens & & & & 1.00 & 0.04 & 0 & 2 \\
\hline Total area & & & & 79.0 & 35.78 & 16.1 & 502.4 \\
\hline
\end{tabular}
of residential properties in the data set that we used, containing the information of 59,027 sold and 128,090 unsold assets. The relevant details and descriptive statistics are summarized in Table 1.

Table 1. Summary statistics of the annual data in 2011-2018

As listed in Table 1, the number of sold monotonically increases during the year from 2011 to 2018 . The annual mean sale price per square meters of sold increases until to 2017 and declines slightly at 2018. Overall, it 
increases from $¥ 39506.9$ to $¥ 48340.4$ during the eight years, and the mean sale price is $¥ 44165$.4, a little smaller than the mean list price $¥ 45727.8$. The units stay on the market have a mean time of 156 days, among which $16.3 \%$ of the units was sold in one month, and about $50.2 \%$ was sold within 131 days. The mean sale area is $79.0 \mathrm{~m}^{2}$ with the minimum and maximum area are $16.1 \mathrm{~m}^{2}$ and $502.4 \mathrm{~m}^{2}$, respectively.

To estimates sellers' bargaining power, the aggregate data of mean logarithmic list prices ( $\mathrm{Pl}$ ), mean logarithmic sale prices (Ps), the share of transactions that occurred below the list price, and mean of days that a property stays on the market (TOM) are needed. The constants of daily discount rate $r$ and parameter $\lambda$ are normalized to 0.0001 and 1, respectively, the same as what has been set in the work of Carrillo (2013). The annual data and calculated sellers' bargaining power are listed in Table 2 .

Table 2. Parameters for the sellers' bargaining power

\begin{tabular}{|c|c|c|c|c|c|c|c|}
\hline \multirow[b]{2}{*}{ year } & obs. & obs. & \multirow{2}{*}{$\begin{array}{c}\text { Share } \\
(\mathrm{Ps}<\mathrm{Pl})\end{array}$} & \multirow[b]{2}{*}{ TOM } & \multirow[b]{2}{*}{ Ps } & \multirow[b]{2}{*}{$\mathrm{Pl}$} & \multirow[b]{2}{*}{$\omega_{t}$} \\
\hline & $\begin{array}{l}\text { SOLD } \\
\text { Ps }<\mathrm{Pl}\end{array}$ & SOLD & & & & & \\
\hline 2011 & 42 & 120 & 0.3500 & 108.55 & 10.56 & 10.06 & 0.96 \\
\hline 2012 & 78 & 198 & 0.3939 & 180.32 & 10.54 & 10.02 & 0.94 \\
\hline 2013 & 206 & 598 & 0.3445 & 153.93 & 10.54 & 10.38 & 0.89 \\
\hline 2014 & 396 & 872 & 0.4541 & 186.31 & 10.54 & 10.51 & 0.78 \\
\hline 2015 & 2,528 & 5,117 & 0.4940 & 196.34 & 10.55 & 10.57 & 0.73 \\
\hline 2016 & 5,686 & 12,259 & 0.4638 & 187.10 & 10.69 & 10.65 & 0.81 \\
\hline 2017 & 8,113 & 17,618 & 0.4605 & 171.25 & 10.81 & 10.79 & 0.78 \\
\hline 2018 & 9,919 & 22,245 & 0.4459 & 151.37 & 10.73 & 10.77 & 0.72 \\
\hline
\end{tabular}

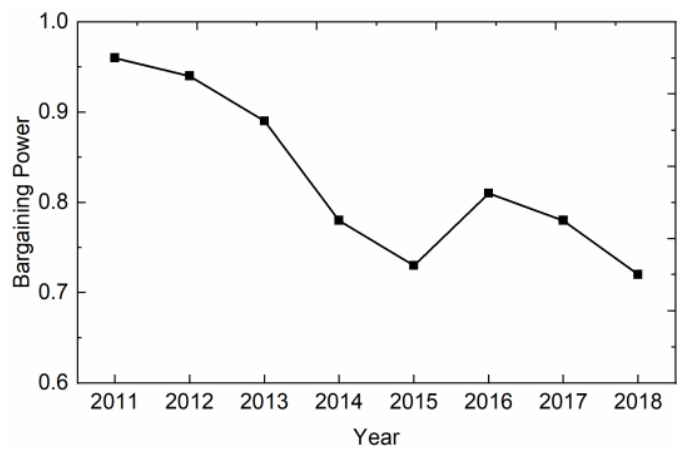

Figure 1. Sellers' bargaining power calculated from aggregate annual data of Shanghai, China

Figure 1 shows the trend of sellers' bargaining power over the time from 2011 to 2018 . It is can be seen that the sellers' bargaining power is larger than 0.5 overall this period, suggesting that the sellers have a bargaining advantage over buyers. This is in line with the general knowledge of China's real estate market, which is seller's market in the past decades since the reform of the urban housing system. The sellers' bargaining power can be as high as 0.95 at 2011. To regulate the housing market, the government has issued a number of detailed rules to prevent the emergence of the real estate bubbles. To name a few, in 2011, the government of Shanghai stipulates that the registered residents possessing more than two houses in Shanghai or the non-registered residence possessing more than one house in Shanghai cannot buy another house. The intervention policy for the subscription qualification of buyers is further tightened, and the tax supervision in housing transactions is strengthened in 2012, and the down payment proportion and loan interest rate of the second house are increased in 2013. Effectively, the buyers and developers fall into a wait-and-see state and the sellers' bargaining power decreases radically during 2012 and 2013. In 2014, although the restrictions on purchase of real estate is not loosen, some remedial measures are made such as the loan interest rate of individual housing provident fund is lowered, which promotes the demand for rigidity and improvement to enter the market actively. Particularly, in 2015, destocking is the main theme of the real estate market, and the credit easing policies stimulates the market. Accordingly, the decrease of sellers' bargaining power during 2013-2014 slows down, and the bargaining power increase again due to the heating up of market since the end of 2015. Therefore, in 2016, the most stringent new policies known as "Shanghai nine rules" are issued, and in 2017 more series of regulatory policies are enacted and continue to this day. The sellers' bargaining power decreases from 2016 to 2018. 
The price index is estimated by using the individual-level housing transaction data. According to Heckman's two-step estimation model, the dependent variable in the probit model is the dummy variable, representing whether to sell the asset or not, which is defined as Tra_dummy in Table 3. In the selection-corrected hedonic price model, the dependent variable is the natural logarithm of the property purchase price per square meter of real estate, labeled as $I n \_p r i c e$ in Table 4. In the two models, time-dummy is the same, with the variables of 2011 being the base-year data. The explanatory variables include five geographical region dummy variables and five Hedonic variables. The property-specific location variables include Xuhui, Yangpu, Songjiang, Pudong districts, where Minhang district is the base district. Hedonic variables include number of bedrooms, number of bathrooms, number of living rooms, number of kitchens and property areas. The natural logarithm of the property area is defined as ln_area. The results of Heckman's two-step estimation are presented in Table 3 and Table 4.

Table 3. Results of probit model of property sale probability in the first step of Heckman process

\begin{tabular}{lcccccc}
\hline \multicolumn{7}{c}{ Dependent Variable: Tra_dummy } \\
\hline Explanatory variable & Coef. & Std. Err. & $\mathrm{z}$ & $\mathrm{P}>|\mathrm{z}|$ & {$[95 \%$ Conf. Interval] } \\
\hline Time dummies & & & & & & \\
2012 & -0.266 & 0.068 & -3.92 & 0.000 & -0.339 & -0.133 \\
2013 & -0.203 & 0.042 & -4.79 & 0.000 & -0.286 & -0.120 \\
2014 & -0.183 & 0.036 & -5.01 & 0.000 & -0.254 & -0.111 \\
2015 & -0.473 & 0.020 & -23.87 & 0.000 & -0.512 & -0.434 \\
2016 & -0.916 & 0.016 & -55.64 & 0.000 & -0.949 & -0.884 \\
2017 & -0.742 & 0.016 & -45.79 & 0.000 & -0.773 & -0.710 \\
2018 & -0.463 & 0.016 & -28.64 & 0.000 & -0.495 & -0.431 \\
\hline Geog. loc. dummies & & & & & & \\
Xuhui district & -0.026 & 0.012 & -2.24 & 0.025 & -0.049 & 0.003 \\
Yangpu district & 0.043 & 0.013 & 3.42 & 0.001 & 0.018 & 0.067 \\
Songjiang district & -0.009 & 0.011 & -0.80 & 0.427 & -0.030 & 0.013 \\
Pudong district & 0.007 & 0.008 & 0.86 & 0.392 & -0.009 & 0.024 \\
\hline Hedonic variables & & & & & \\
Bedrooms & -0.028 & 0.007 & -4.24 & 0.000 & -0.042 & -0.015 \\
Bathrooms & 0.009 & 0.009 & 0.97 & 0.330 & -0.009 & 0.027 \\
Livings & -0.007 & 0.008 & -0.93 & 0.353 & -0.022 & 0.008 \\
Kitchens & -0.035 & 0.076 & -0.46 & 0.644 & -0.184 & 0.114 \\
ln_area & 0.119 & 0.012 & 7.86 & 0.000 & 0.090 & 0.149 \\
cons & -0.234 & 0.015 & -2.52 & 0.012 & -0.416 & -0.052 \\
\hline
\end{tabular}

Table 4. Results of the selection-corrected hedonic price model in the second step of Heckman process

\begin{tabular}{|c|c|c|c|c|c|c|}
\hline \multicolumn{7}{|c|}{ Dependent Variable: $\ln \_$price } \\
\hline Explanatory variable & Coef. & Std. Err. & $\mathrm{z}$ & $\mathrm{P}>|\mathrm{z}|$ & \multicolumn{2}{|c|}{ [95\% Conf. Interval] } \\
\hline \multicolumn{7}{|l|}{ Time dummies } \\
\hline 2012 & -0.164 & 0.030 & -5.47 & 0.000 & -0.223 & -0.105 \\
\hline 2013 & -0.187 & 0.020 & -9.27 & 0.000 & -0.227 & -0.147 \\
\hline 2014 & -0.151 & 0.018 & -8.42 & 0.000 & -0.186 & -0.116 \\
\hline 2015 & -0.121 & 0.037 & -3.25 & 0.001 & -0.194 & -0.048 \\
\hline 2016 & 0.024 & 0.076 & 0.31 & 0.755 & -0.126 & 0.173 \\
\hline 2017 & 0.099 & 0.061 & 1.64 & 0.102 & -0.020 & 0.219 \\
\hline 2018 & 0.048 & 0.037 & 1.32 & 0.188 & -0.024 & 0.120 \\
\hline \multicolumn{7}{|l|}{ Geog. loc. dummies } \\
\hline Xuhui district & 0.394 & 0.005 & 78.65 & 0.000 & 0.384 & 0.404 \\
\hline Yangpu district & 0.236 & 0.006 & 39.70 & 0.000 & 0.225 & 0.248 \\
\hline Songjiang district & -0.237 & 0.004 & -54.34 & 0.000 & -0.246 & -0.229 \\
\hline Pudong district & 0.104 & 0.003 & 30.69 & 0.000 & 0.097 & 0.110 \\
\hline ln_area & -0.082 & 0.007 & -11.17 & 0.000 & -0.097 & -0.068 \\
\hline _cons & 10.973 & 0.112 & 98.36 & 0.000 & 10.754 & 11.192 \\
\hline \multicolumn{7}{|l|}{ mills } \\
\hline lambda & -0.293 & 0.144 & -2.03 & 0.042 & -0.575 & -0.011 \\
\hline rho & -0.761 & & & & & \\
\hline sigma & 0.385 & & & & & \\
\hline
\end{tabular}


The results of the probit estimation property sale probability are presented in Table 3. It is found that the number of bedrooms has negative significant on the probability of sale, while the construction area has a positive significant effect. The number of bathrooms, living rooms and kitchens is not statistically significant. Table 4 reports the results of selection-corrected hedonic price model. The coefficient of lambda is statistically significant, indicating the existence of sample selection bias. The selection-bias-corrected hedonic price index is described by the time-dummy estimation coefficients $\hat{\beta}_{t}$ in Table 4 . It is can be seen that the sale price is significantly related to geographical region, in line with our general perceptions. In addition, the construction area has a significant negative dependence. The estimated coefficient sigma $(\hat{\sigma})$ presented in Table 4 and the estimated coefficient of the time-dummy variable $\left(\hat{\gamma}_{t}\right)$ reported in Table 3 as well as the sellers' bargaining power are used to construct the correction term of the demand-side price index in Eq. (16).

Figure 2 shows the residential price indices constructed under different cases. Under some special choice of sellers' bargaining power, the method presented here reduces correctly to pervious price index. For instance, if $\omega=0.0$, the result is the selection-bias-corrected price index, while if assuming the sellers and buyers has the same bargaining effect, i.e., $\omega=0.5$, the price index is what has been reported by Fisher et al. (2003). The price index with time-dependent bargaining power displays slightly greater amplitude and volatility as compared to the case of constant value of 0.5 . The price index shows decease trend in 2012 to 2013, in line with the tightening policies of the real estate market. Moreover, the slight increase in 2013-2014 and sharp increase in 2015-2016 is led by the weak remedies in 2014 and strong incentives in the end of 2015, respectively. The trend during 2017-2018 also tallies with strict tightening policies. The consistency is not surprising since the price index is demand-side index and many of the policies are designed to restrain buyers such the limiting the number of houses they can possess.

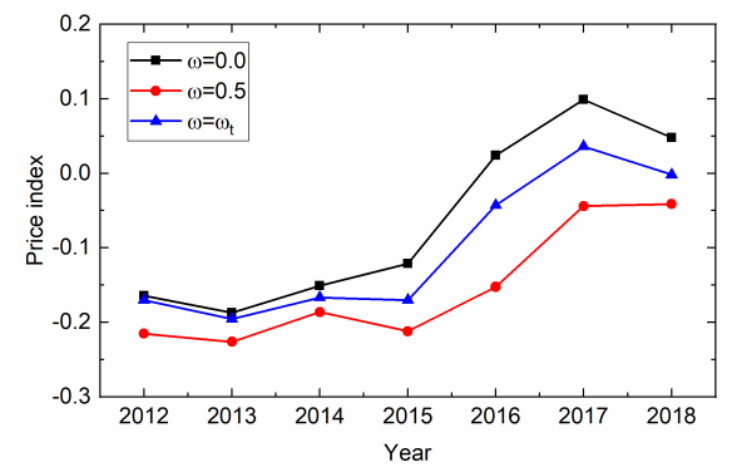

Figure 2 . The residential price index constructed by only selection bias correction $(\omega=0.0)$, and selection bias correction with constant equal bargaining power between sellers and buyers $(\omega=0.5)$, and time dependent sellers' barging power $\left(\omega=\omega_{t}\right)$, respectively.

\section{Conclusions}

The residential price index plays a crucial role in monitoring the situation of real estate market. To regulating the real estate market, many policies distributed by the government are aimed at market participants. However, the conventional approach of constructing price index cannot consider the role of participants such as the objectively existent bargaining process. In this work, we present an improved price index model, which considers the participants' bargaining effect by Nash bargaining analysis and Heckman's two-step regression. The response of participants to the policies also can be implied in the factor of bargaining power. As an example, this price index model is applied to study the residential market of Shanghai, China. The variation trend of price index can reasonably reflect the market changes as well as the role of regulatory policies. This improved price index is a more general model, which can reduce correctly to previous models if we consider the more restrictive situations.

\section{References}

Baile, M., Muth, R., \& Nourse H. (1963). A regression method for real estate price index construction. Journal of the American Statistical Association, 58(304), 933-942. https://doi.org/10.1080/01621459.1963.10480679

Carrillo, P. E. (2013). To sell or not to sell: Measuring the heat of the housing market. Real Estate Economics, 41(2), 310-346. https://doi.org/10.1111/reec.12003 
Devarakonda, R., Reuer, J. J., \& Tadikonda, D. D. H (2016). The bargaining effect of startup founders and venture capitalists on value-capturing rights. Academy of Management Proceedings, 2016(1), 17241. https://doi.org/10.5465/ambpp.2016.17241abstract

Dijk, D. V., Geltner, D., \& Minne, A. V. D. (2018). Revisiting supply and demand indexes in real estate. DNB Working Papers 583, Netherlands Central Bank, Research Department. https://doi.org/10.15396/eres2018_41

Fisher, J., Gatzlaff, D., Geltner, D., \& Haurin, D. (2003). Controlling for the impact of variable liquidity in commercial real estate price indices. Real Estate Economics, 31(2), 269-303. https://doi.org/10.1111/1540-6229.00066

Fisher, J., Geltner, D., \& Pollakowski, H. (2007). A quarterly transactions-based index of institutional real estate investment performance and movements in supply and demand. The Journal of Real Estate Finance and Economics, 34(1), 5-33. https://doi.org/10.1007/s11146-007-9001-6

Francke, M. K. (2010). Repeat sales index for thin markets. The Journal of Real Estate Finance and Economics, 41(1), 24-52. https://doi.org/10.1007/s11146-009-9203-1

Francke, M. K., \& Minne A. V. D. (2017). The hierarchical repeat sales model for granular commercial real estate and residential price indices. The Journal of Real Estate Finance and Economics, 55(4), 511-532. https://doi.org/10.1007/s11146-017-9632-1

Gatzlaff, D. H., \& Haurin, D. R. (1997). Sample selection bias and repeat-sales index estimates. The Journal of Real Estate Finance and Economics, 14(1/2), 33-50. https://doi.org/10.1023/A:1007763816289

Gatzlaff, D. H., \& Haurin, D. R. (1998). Sample selection and biases in local house value indices. The Journal of Urban Economics, 43(2), 199-222. https://doi.org/10.1006/juec.1997.2045

Genesove, D. \& Han, L. (2012). Search and matching in the housing markets. Journal of Urban Economics, 72(1), 31-45. https://doi.org/10.1016/j.jue.2012.01.002

Gong, P., Zhang, Y., \& Zhao, H. (2018). Divergence in reservation prices and its impact on housing market liquidity: A theoretical analysis. Journal of Management Science and Engineering, 3(3), 141-157. https://doi.org/10.3724/SP.J.1383.303008

Harding, J. S., Rosenthal, S., \& Sirmans, C. F. (2003). Estimating bargaining power in the market for existing homes. The Review of Economics and Statistics, 85(1), 178-188. https://doi.org/10.1162/003465303762687794

He, L. Y., \& Wen, X. C. (2017). Population growth, interest rate, and housing tax in the transitional China. Physica A: Statistical Mechanics and its applications, 469, 305-313. https://doi.org/10.1016/j.physa.2016.11.057

Heckman, J. J. (1979). Sample selection bias as a specification error. Econometrica, 47(1), 153-161. https://doi.org/10.2307/1912352

Krainer, J. (2001). A theory of liquidity in residential real estate markets. Journal of Urban Economics, 49(1), 32-53. https://doi.org/10.1006/juec.2000.2180

Krainer, J., \& LeRoy, S. F. (2002). Equilibrium valuation of illiquid assets. Economic Theory, 19(2), 223-242. https://doi.org/10.1007/PL00004214

Li, R. Y. M., \& Chau, K. W. (2016). Econometric analyses of international housing markets. Abingdon and New York: Routledge.

Li, R. Y. M., \& Li, H. C. Y. (2018). Have housing prices gone with the smelly wind? Big data analysis on landfill in Hong Kong, Sustainability, 10(2), 341. https://doi.org/10.3390/su10020341

Lin, Z., \& Vandell, K. D. (2007). Illiquidity and pricing biases in the real estate market. Real Estate Economics, 35(3), 291-330. https://doi.org/10.1111/j.1540-6229.2007.00191.x

Liu, C., Zheng, Y., Zhao, Q., \& Wang C. (2020). Financial stability and real estate price fluctuation in China. Physica A: Statistical Mechanics and its applications, 540, 122980. https://doi.org/10.1016/j.physa.2019.122980

Merlo, A., \& Ortalo-Magne, F. (2004). Bargaining over residential real estate: Evidence from England. Journal of Urban Economics, 56(2), 192-216. https://doi.org/10.1016/j.jue.2004.05.004

Munneke, H. J., \& Slade B. A. (2000). An empirical study of sample-selection bias in indices of commercial real 
estate. The Journal of Real Estate Finance and Economics, 21(1), 45-64. https://doi.org/10.1023/A:1007861303058

Munneke, H. J., \& Slade, B. A. (2001). A metropolitan transaction-based commercial price index: A time varying parameter approach. Real Estate Economics, 29(1), 55-84. https://doi.org/10.1111/1080-8620.00003

Rosen, S. (1974). Hedonic prices and implicit markets: Product differentiation in pure competition. Journal of Political Economy, 82(1), 34-55. https://doi.org/10.1086/260169

Selcuk, C. (2013). Motivated sellers and predation in the housing market. Economic Modelling, 32, $203-214$. https://doi.org/10.1016/j.econmod.2013.02.005

Wallace, N. E., \& Meese, R. A. (1997). The construction of residential housing price indices: A comparison of repeat-sales, hedonic-regression, and hybrid approaches. The Journal of Real Estate Finance and Economics, 14(1/2), 51-73. https://doi.org/10.1023/A:1007715917198

Wen, X. C., \& He, L. Y. (2015). Housing demand or money supply? A new Keynesian dynamic stochastic general equilibrium model on Chia's housing market fluctuations. Physica A: Statistical Mechanics and its applications, 432, 257-268. https://doi.org/10.1016/j.physa.2015.03.040

Yang, B., Long, W., Peng, L., \& Cai, Z. (2020). Testing the predictability of U.S. housing price index returns based on an IVX-AR model. Journal of the American Statistical Association, 1-22. https://doi.org/10.1080/01621459.2019.1686392

Zheng, X., Chau, K. W., \& Eddie, C. M. H. (2015). Liquidity risk and cross-sectional return in the housing market. Habitat International, 49, 426-434. https://doi.org/10.1016/j.habitatint.2015.06.012

Zhou, W. X., \& Sornette D. (2008). Analysis of the real estate market in Las Vegas: Bubble, seasonal patterns, and prediction of the CSW indices. Physica A: Statistical Mechanics and its applications, 387(1), 243-260. https://doi.org/10.1016/j.physa.2007.08.059

\section{Copyrights}

Copyright for this article is retained by the author(s), with first publication rights granted to the journal.

This is an open-access article distributed under the terms and conditions of the Creative Commons Attribution license (http://creativecommons.org/licenses/by/4.0/). 